\title{
A Hadoop-Based Online Teaching Model of "VisibleBody"
}

\author{
https://doi.org/10.3991/ijet.v16i11.23219
}

Haiyan Deng

Xiangnan University, Chenzhou, China

Chunyan $\left.\mathrm{Li}{ }^{(}\right)$

Hunan University of Chinese Medicine, Changsha, China

$139755136180163 . \mathrm{com}$

\begin{abstract}
It is the responsibility of nursing educators to cultivate community nursing professionals who can adapt to the post and meet social needs. However, there exist some problems in current community nursing curriculum education such as inconsistent teaching content and different levels of teachers' lecturing. In this study, a good educational resource ecosystem was established in virtue of the mighty flexibility and expansibility of hadoop technology, the resources in community nursing teaching courses are stored in the hadoop cloud resource library. At the same time, community nursing online course resources were newly designed and improved through HdoopYarn resource scheduling algorithm, thereby realizing the establishment of a virtual experimental environment for nursing major. VisibleBody virtual medical software was applied to the internship and practical training, specifically in 12 knowledge units of 5 modules according to the characteristics of this course, demonstrating a deeplevel human body structure and accurate nursing operation. An objective structured clinical examination mode was adopted in the teaching method, which could create a simulated community nursing situation during teaching, so that students could complete standardized patient assessment and examination within the given time, and accept testers' questions and acquire results. It was found from the teaching practice that the application of teaching model is conductive to enhancing students' academic performance and improving community nursing capabilities, including problem-solving competence, communication skills, teamwork ability, etc.
\end{abstract}

Keywords - Hadoop technology; VisibleBody; community nursing; OSCE mode

\section{Introduction}

Community nursing is one of the components of community health services. However, currently, there exist the problem of a lack of community nursing professionals. Optimizing curriculum and strengthening talent training are important methods of facilitating community nursing development, as well as key strategies to meet com- 
munity nursing needs and follow the development of the times. Therefore, it is of special significance to strengthen the construction of community nursing courses [1]. Modern community nursing has gone beyond the traditional concepts and scope, gradually transferred to a variety of contents and roles such as health education, consultation, management, and coordination, thereby setting higher requirements for community service workers.

However, due to the highly theoretical content of the "Community Nursing" course, lack of attraction, and similar contents with the courses of internal medicine, gynecology, pediatrics in the current community nursing talent training, the teaching process has not yielded satisfactory results. Every year, few students can really master the key and difficult points of community nursing work after the course is over [2]. Therefore, it is a must to conduct teaching reform of community nursing course. The research team attempted to propose an Internet-based "Community Nursing" tutorial, in which the teaching design was effectively integrated with objective structured clinical examinations through Hadoop technology with "VisibleBody" virtual medical teaching software, in hope of cultivating mor qualified community nursing staff under this teaching model.

\section{State of the Art}

Community nursing is ultimately aimed at promoting and maintaining the health of the community population by comprehensively applying the theories and techniques of nursing and public health to the population in communities through the integration with medical treatment, prevention, and health care into the curriculum at the core of providing services. This course plays a critical role in the development of nursing, as well as an essential part of the nursing discipline. The concept of community nursing was initially proposed in the United States, followed by the rapid development of community nursing curriculum under the strong financial support of the US government and the powerful guidance of educational policies. In British medical schools, the cultivation standards of community nursing skills shall be higher than those of clinical hospitals. Regarding teaching methods, US community nursing course adheres to classroom lecturing, adopts student-centered teacher-student collaborative model and flexible teaching methods, such as problem teaching [3], peer instruction [4] and so on. The studies of Day-Black et al. [5] showed that the application of service learning in community nursing teaching can effectively accelerate nursing teaching reform. The studies of Vignato et al. [6] showed that innovative pilot model is conductive to the diversity of nursing education. Lambert et al. [7] enhanced the community nursing teaching level of undergraduate nursing students by adopting innovative teaching strategies. With regard to teaching design, existing nursing educators attach importance to the integration of multiple disciplines. For example, Im \& Kong [8] integrated the evidence-based nursing concept in community nursing, and Mabel proposed to penetrate scientific research into the community to cultivate community nursing. Zheng et al. [9] proposed that the practical teaching of community nursing course has greater significance. Zheng et al. [9] attempted to strengthen nurs- 
ing students' clinical experience in community nursing teaching, not only for the purpose of enhancing their clinical skills, but also providing more employment and learning opportunities. In conclusion, developed countries attached greater importance to community nursing course and launched community nursing talent cultivation earlier with a more advanced education level of community nursing talent training. Therefore, it is worth learning lessons from developing countries.

Few in-depth theoretical and practical studies of community nursing talent training strategy have been conducted in China. Some scholars believe that the foundation for the standardized training of community nurses lies in the improvement of teaching reform of community nursing courses, as well as an important guarantee for cultivating community nursing talents. Miao et al. [10] proposed a community nursing teaching method at the core of vocational ability, and set up vocational capability learning goals through the optimization of the structure of teaching materials, and paid attention to carry out professional social practice for the enhancement of students' vocational ability. Practice proved that this teaching mode is conductive to the enhancement of students' professional capabilities, learning interest and sense of identity with community nursing work. Lin et al. [11] attempted to apply sitcom performances in community nursing teaching. It was found after the course practice that the average score of the final exam of the experimental class improved significantly. $87.5 \%$ of students believed that the sitcom performance could help stimulate learning interest and enhance self-learning capabilities. Shen et al. [12] applied the Conceive-DesignImplement-Operate (CDIO) teaching model to community nursing teaching. It was found that this teaching model can strengthen students' autonomous learning competence and enhance the satisfaction of teaching. Jiao et al. [13] made an explorative attempt to develop a teaching method of "Internet + health promotion volunteers" inside and outside class, and applied this teaching method to the practical teaching of "Community Nursing". Through the comparison of teaching effect, it was found that this teaching method can strengthen students' communication skills, health education competence and teamwork capabilities. However, a lot of existing documents show that there remain some inadequacies in the teaching community nursing course, such as backward teaching methods, teachers' ignorance of cultivating students' capabilities of active thinking and autonomous learning ability; over-emphasis of teaching form on teacher's leading role in teaching and ignorance of students' dominant position. Such teacher-oriented teaching activities with outdated methods and singleevaluation is not conductive to establishing a harmonious teacher-student relationship and cultivating students' community nursing capacities.

In the meantime, with the development of information technology and the popularization of the Internet, online learning has been extensively applied in educational field. Despite the trend of actively promoting the "Internet + " teaching informatization, advocating to explore new education service models, encouraging schools to utilize digital education resources and education service platforms, gradually discovering new models of network-based education, and accelerating the transformation of various education service model in educational circle, few studies have focused on the application of new Internet information technology in community nursing course. In view of this, this research proposed a Hadoop-based virtual simulation platform to 
create a real-world community nursing virtual environment through modern science and technologies, thereby achieving natural interactions between students and virtual learning environment in virtue of visual, auditory, and tactile sensing channels; at the same time, new Visible Body software was used in the teaching classroom to produce an interesting and dynamic video; secondly, an objective structured clinical examination (OSCE) was adopted in the teaching method). OSCE [14] can comprehensively evaluate the core competence of nursing professionals, which creates simulated community nursing situations so that students can complete standardized patient assessments and examinations within a specified time, propose diagnostic results and treatment methods, and accept questions from testers and acquire results. To sum up, the teaching model applied in this study can hopefully provide some references for the reform of community nursing course reform, and better cultivate community nursing talents to meet community nursing market demand.

\section{Establishment of Hadoop-Based Online Teaching Model of "VisibleBody"}

\subsection{Application of application of OSCE model in online nursing teaching}

In the conventional clinical nursing evaluation system, written examination and clinical operation examinations are often combined for assessment, which is single in the form of evaluation and lacks comprehensive evaluation of nursing staff. OSCE method (Objective structured clinical examination, OSCE) with comprehensive assessment content can avoid the above problems in written examination and lower the biased results of the assessment, thereby fully integrating the evaluation with the educational goals to guarantee a scientific evaluation by means of hierarchical evaluation method. OSCE examination model is conductive to examination and evaluation from the three aspects of spirit, cognition and emotion. As community nursing has attracted greater attention in China, nursing qualification examinations in China will develop towards a more scientific, systematic, and transformational direction. OSCE method will become an important model in the future nursing qualification examinations. In view of this, this study firstly integrated OSCE method in the teaching process of community nursing. The online teaching mode after integration is shown in Figure 1. 


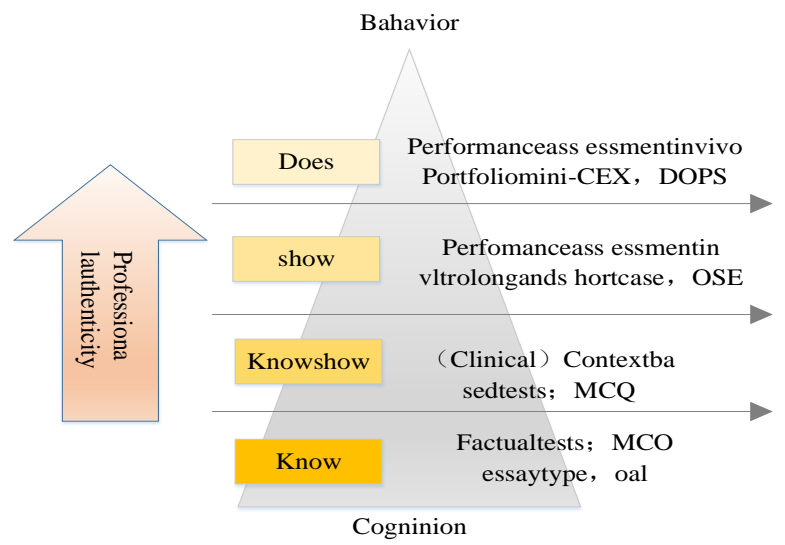

Fig. 1. OSCE model construction in online nursing teaching

\subsection{Hadoop-based community nursing teaching course resource design}

Based on Hadoop, a distributed file system (Hadoop Distributed File System) was implemented, including a component of HDFS with the characteristic of high fault tolerance, which was designed to be deployed on low-cost hardware; and its high throughput (high throughput) was used to access application data, applicable to application programs with very large data sets, thereby providing necessary technical guarantee for community nursing online course implementation and design. In the era of big data, with tremendous online community nursing data, Hadoop is feasible in colleges. The specific design framework is as follows:

1. The basic composition of Hadoop technology was clarified

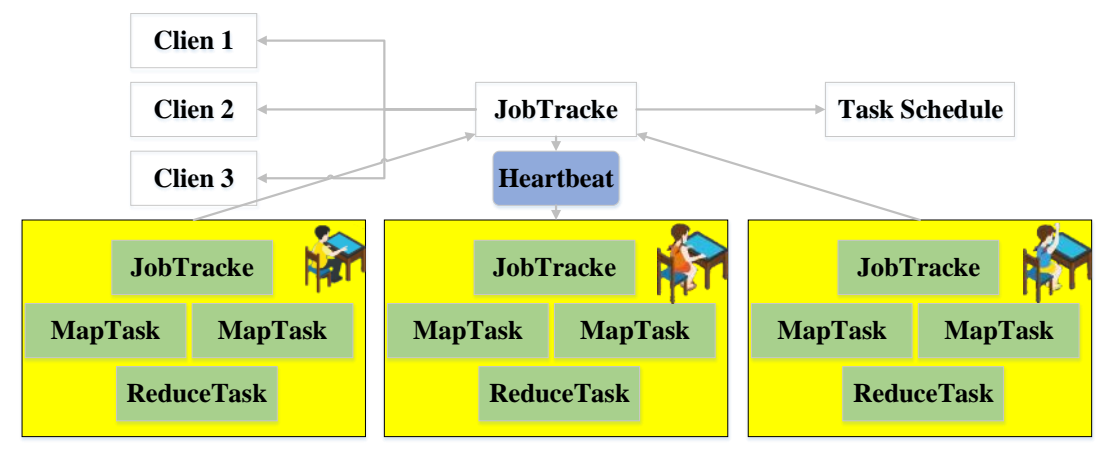

Fig. 2. The basic structure of Hadoop1.0 in the online course

Figure 2 shows arduous tasks for JobTracker has arduous and single function of Task Tracker. This demonstrated an imbalanced proportion of tasks for both, leading to a single-node bottleneck in the operation performance of Hadoop 1.0. This required 
for the allocation of tasks and resources by resource management system, and the optimization of Hadoop 1.0 functions.

2. Determination of the improved HadoopYarn resource scheduling algorithm

In this research, community nursing online course resources were newly designed and improved using the improved HdoopYarn resource scheduling algorithm. The HadoopYarn resource scheduling algorithm is as follows.

Considering resources and task items in the resource scheduling algorithm not constantly corresponding to each other, the correlation between the task items and the resource items needs to be established to achieve the compatibility between both. The specific process is as follows:

$$
S=\left\{T, R, D, M_{t v}, M_{v d}\right\}
$$

In the above formula, $\mathrm{s}$ represents a comprehensive scheduling process, $T=\left\{t_{1}, t_{2}, \ldots t_{n}\right\}$ represents a set of task numbers, $\mathrm{R}=\left\{\mathrm{r}_{1}, r_{2}, \ldots r_{n}\right\}$ represents a set of resource numbers, and $D=\left\{\mathrm{d}_{1}, d_{2}, \ldots d_{n}\right\}$ represents a set of physical device numbers. $M_{t r}$ represents the mapping relationship between resources and tasks, and $M_{r d}$ represents the mapping relationship between resources and physical devices.

Wherein, task allocation for $M_{t r}$ is completed by the computer center, and $M_{r d}$ refers to that resource is scheduled by the resource scheduler to the corresponding storage device. Therefore, resource scheduling is mainly aimed for the scheduling of resources to the storage device.

Assume that task $t_{i}$ is mapped to resource $v_{j}$ through mapping relationship $\mathrm{M}$, and the resource $v_{j}$ is scheduled to a physical device $d_{k}$ through a scheduling algorithm, and expected execution time of the process that allocating task $t_{i}$ resources to the physical device through the computer center is expressed as $\operatorname{ETD}\left(t_{i}, d_{k}\right)$. The distribution matrix for task $\mathrm{T}$ allocated to physical device $\mathrm{D}$ is expressed as:

$$
E T D_{m n}=\operatorname{ETD}\left(t_{i} M_{t r}, d_{k}\right) 1 \leq i \leq m, 1 \leq k \leq n
$$

The above formula represents the execution time matrix in which in tasks are allocated to $\mathrm{n}$ devices through resource mapping relationship $t_{i} M_{t i}$.

The earliest completion time of task $t_{i}$ on the physical device $d_{k}$ through the mapping relationship $m_{t r}$ is expressed as:

$$
\operatorname{Finish}\left(t_{i} M_{t r}, d_{k}\right)=\operatorname{Start}\left(d_{k}\right)+\operatorname{ETD}\left(t_{i} M_{t r}, d_{k}\right)
$$

In the formula, $\operatorname{Start}\left(d_{k}\right)$ represents the earliest start time available for task execution on the physical device $d_{k}$. Therefore, the total time for task allocation on the physical device $d_{k}$ can be expressed by the following formula: 


$$
\begin{aligned}
\operatorname{Start}\left(d_{k}\right) & =\sum_{i=1}^{m} c_{i k} \operatorname{Finish}\left(t_{i} M_{t i}, d_{k}\right) \\
c_{i k} & =\left\{1, t_{i} M_{t r}=d_{k}\right. \\
c_{i k} & =\left\{0, t_{i} M_{t r} \neq d_{k}\right.
\end{aligned}
$$

In the formula, $c_{i k}=1$ represents that the task $t_{i}$ is executed on the physical device $d_{k}$. Therefore, the total time for all tasks executed by the resource scheduler is:

$$
\operatorname{total}(T)=\sum_{k=1}^{n} \operatorname{Sum}\left(d_{k}\right)
$$

The optimization of resource scheduling algorithm aims to minimize the task execution time through resource scheduler, that is, to achieve the minimum value in the above formula. Therefore, the objective function of resource scheduling is:

$$
\operatorname{Coal}(T)=\min \sum_{k=1}^{n} \operatorname{Sum}\left(d_{k}\right)
$$

\section{Application of improved Hadoop Yarn resource scheduling algorithm}

The above conducted a detailed analysis of HadoopYarn resource scheduling algorithm, clarified the goal and process of resource allocation, and proposed a preliminary assumption. Figure 3 shows the resource scheduling algorithm with community nursing online teaching as a case, by which a practical research on the resource mobilization algorithm was performed.

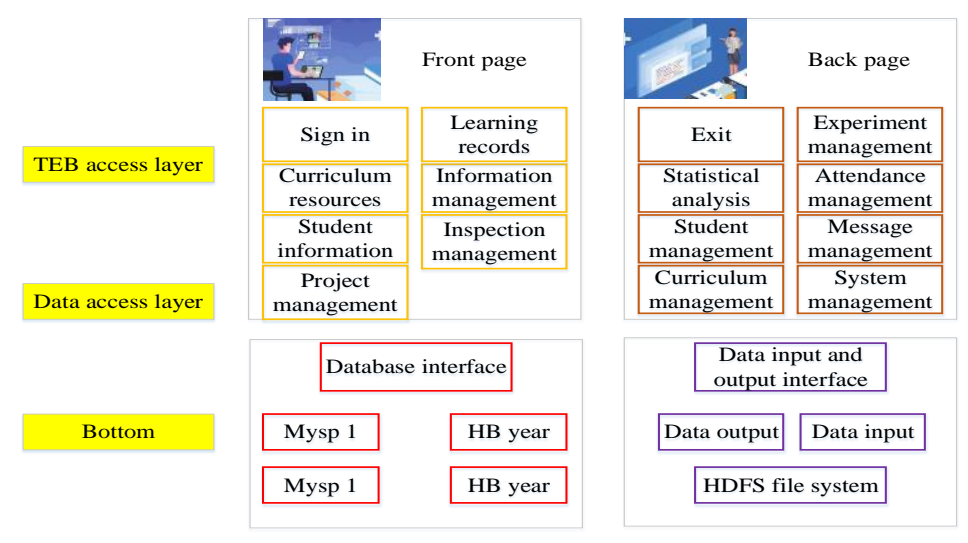

Fig. 3. Improved HadoopYarn resource mobilization algorithm diagram

It can be seen from Figure 3 that Hadoop-based virtual simulation teaching management system can store the teaching resource data in Hadoop-based cloud resource library in virtue of Hadoop storage and flexible expandability, thereby creating a virtual environment. Based on system overall design, this system was designed by 
using Java Web technology and HDFS file system, with Mysql and HBase as the basic database. At the same time, taking full consideration of the principles of system design, this system adopted a layered architecture code, mutually independently used open communication interfaces for lower dependence on overlapping codes, thereby realizing the development of front-end and back-end respectively.

\subsection{Realization of community nursing online teaching model using "VisibleBody" software}

It can be seen from Figure 4 that VisibleBody is a medical software and a website available for viewers' comprehensive understanding of the structure of the human body. The software consists of five modules, each applicable to computers and mobile devices, with Chinese subtitles. Its advantage lies in learning anytime and anywhere without the limitations of time and space, as well as providing some medical terms for students. In this study, "Yisible Body" software was applied to community nursing teaching, the contents of which could enhance students' interest in the core concepts of anatomy and physiology knowledge content. The course with better interface in Chinese and English versions is convenient for Chinese students' use. The software is composed of 12 units, namely, cells and tissues, skin, bone marrow and joints, muscle types, nerves, endocrine, circulation, lymph, breathing, digestion, urinary and reproductive systems. Students, teachers, and educational administrators after login authentication can access to the software homepage for education, learning, and management activities. VisibleBody simulation system is also applicable to classroom teaching to promote learning and cultivate students' independent learning under a hierarchical learning model. Figure 5 shows the scenario of students' learning of online community nursing course through "VisibleBody" software. Figure 6 shows the scenario of the application of "VisibleBody" software in community nursing practice courses by teachers and students. The objective structured clinical examination (OSCE) model was used as the teaching method of this step.

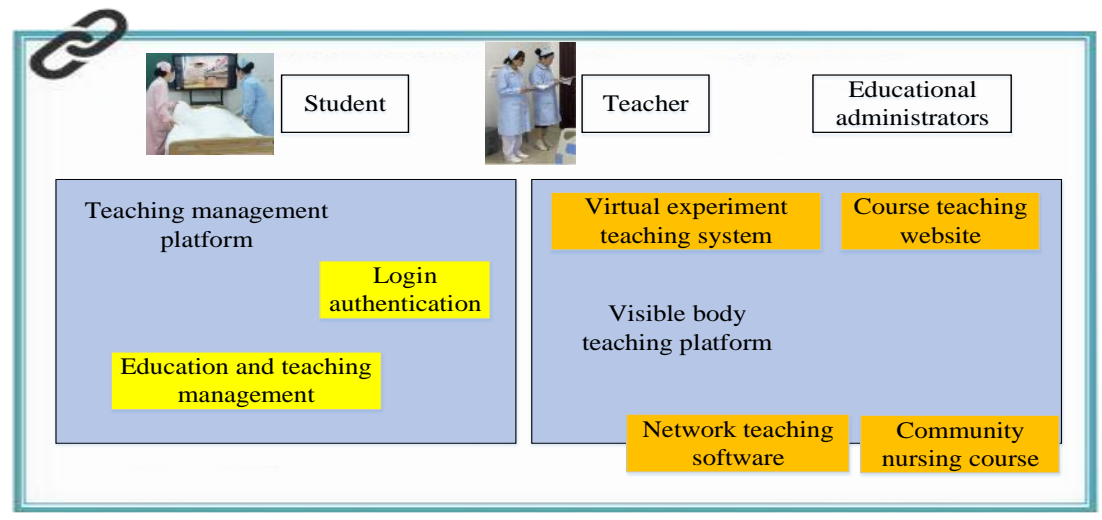

Fig. 4. Community nursing online teaching mode using "VisibleBody" software 


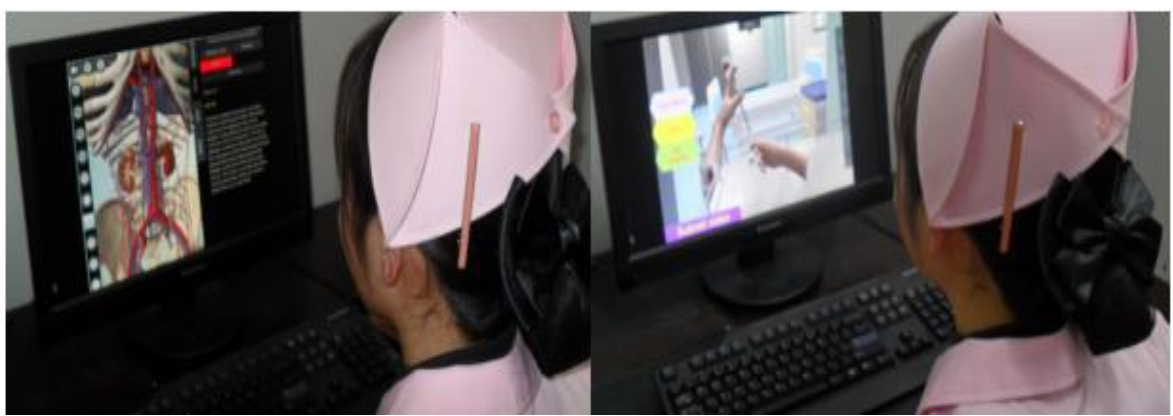

Fig. 5. Scenario of students' learning of online community nursing course through "VisibleBody" software

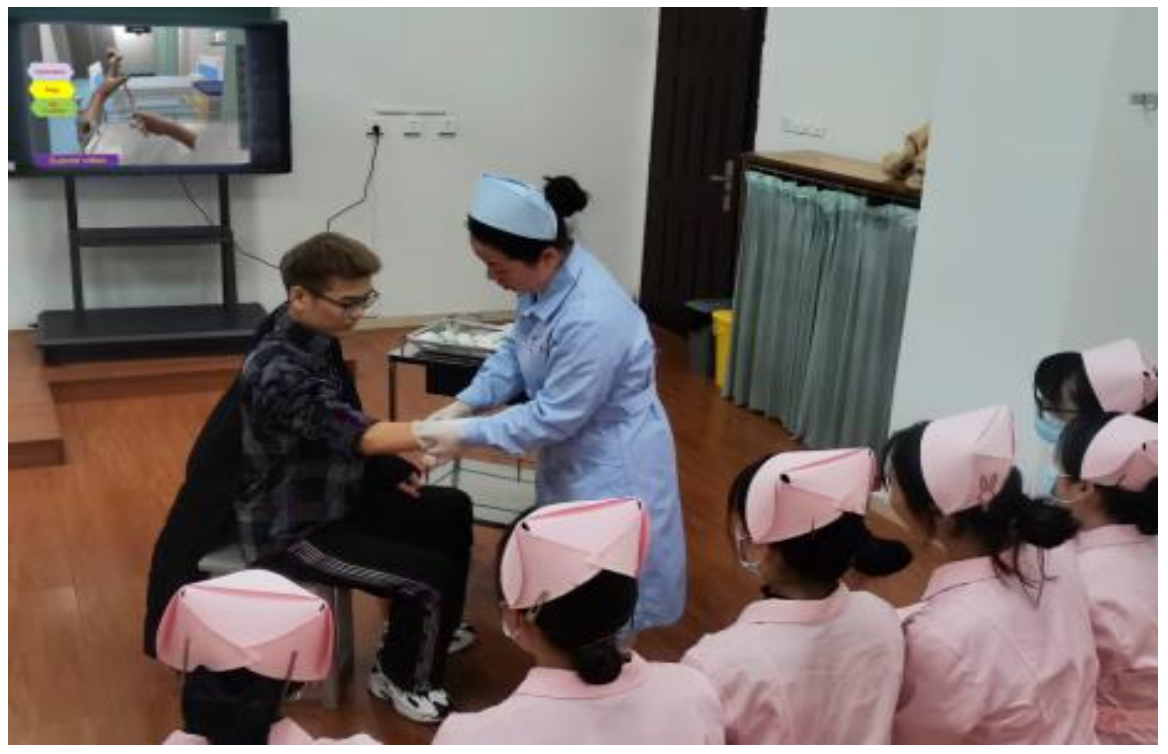

Fig. 6. Application of objective structured clinical examination (OSCE) model in community nursing practical teaching

\section{$4 \quad$ Teaching Example and Effect}

\subsection{Teaching example}

In this research, the sophomore year nursing students of a medical college in $\mathrm{Hu}-$ nan Province were selected as the main research objects. Among them, students from one class were randomly chosen as the control group, and students from the other class were randomly chosen as experimental group. A comparative study of the teaching model between the two groups was performed. The control group contained 25 female students and 8 male students; experimental group contained 26 female stu- 
dents and 8 male students. The age, gender, and freshman professional scores of the students in two groups were verified, and the results showed that $\mathrm{P}>0.05$, indicating that the students in the two classes were eligible for this teaching model practice.

It can be seen from Figure 7 that the OSCE model method combined with the "Visible Body" software were performed on the students in the experimental group. That is, students were regularly organized to attend training every month, received theoretical assessment and skill assessment after the training for judging students' critical thinking ability, behavior attitude, post capacity and comprehensive capabilities. First, a mock assessment team containing teachers and student representatives was established based on the 5W2H principle, including [What (what to do)-what is the goal? Why - whether the goal is supportive for departmental and organizational goal? When (when to start, when to end)-how long is the time limit for the goal? Where-Where to complete it? Who (who will complete it)-who is responsible for the goal? How (how to complete)-what are the key measures for goal execution? How much (how much to complete, how much is the cost)-to what extent is the goal completed, and what resources are needed to support it? Next, a teaching plan was formulated for community nurses, and exam objectives were formulated reasonably according to the plan. The teaching content involved ten most common nursing problems in community nursing work. At the same time, learning scenarios in OSCE mode were provided. Specific measures included the assessment time was controlled within 30 minutes, and the assessment content included whether they were qualified with first aid knowledge and skills, adaptability and response ability, drug use, critical thinking, and other related capabilities. After the completion of the assessment, the teacher scored and commented on the spot, and the students discussed the cases in groups.

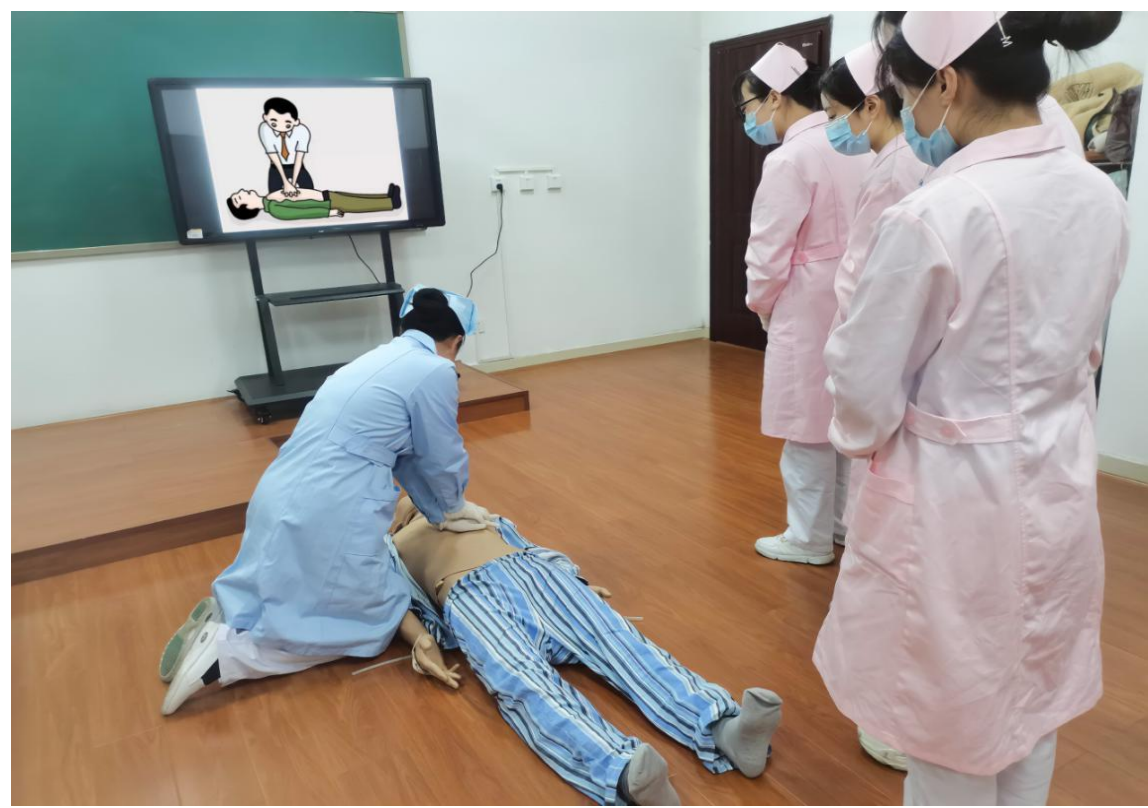

Fig. 7. Scenario of students' learning of OSCE community nursing model approach 


\subsection{Teaching effect}

Table 1. Comparison of students' term-end results in two groups

\begin{tabular}{|l|c|c|}
\hline \multicolumn{1}{|c|}{ Sex } & Theoretical achievements & Operation achievements \\
\hline Experimental group $(\mathrm{n}=34)$ & $80.23 \pm 1.45$ & $93.15 \pm 0.64$ \\
\hline Control group $(\mathrm{n}=33)$ & $74.16 \pm 0.76$ & $88.31 \pm 1.32$ \\
\hline $\mathrm{t}$ & 19.045 & 16.061 \\
\hline $\mathrm{p}$ & 0.000 & 0.000 \\
\hline
\end{tabular}

In this paper, data processing was performed using SPSS 19.0 software. Likert scores and examination results were expressed as " $\mathrm{x} \pm \mathrm{s}$ ", $\mathrm{t}$ for measurement data comparison test, $\mathrm{x}^{2}$ for count data test, and $\mathrm{P}<0.05$ was considered statistically significant.

In the meantime, to investigate the effect of the teaching model on the students' community nursing capacity, evaluation on the basis of community nursing was also performed in this study. In response to the needs of community nursing, with the actual characteristics of students majoring in community nursing fully into consideration, five indicators were ultimately obtained, evaluation intervention ability, communication ability, judgment thinking ability, emergency response ability, and knowledge application ability. In the end, four scoring standards were set for each indicator, excellent, good, fair, and poor. The scoring results were scored from 4-1 points respectively. The scores of the experimental group and the control group according above standard were as table 1 and table 2 :

Table 2. Comparison of students' community nursing ability in two groups

\begin{tabular}{|c|c|c|c|c|c|c|c|c|c|c|c|c|c|c|c|c|c|c|c|c|}
\hline \multirow[t]{2}{*}{ Group } & \multicolumn{4}{|c|}{$\begin{array}{l}\text { Evaluate } \\
\text { problems }\end{array}$} & \multicolumn{4}{|c|}{$\begin{array}{c}\text { Communication } \\
\text { skills }\end{array}$} & \multicolumn{4}{|c|}{$\begin{array}{c}\text { Judgment } \\
\text { thinking }\end{array}$} & \multicolumn{4}{|c|}{$\begin{array}{c}\text { Emergency } \\
\text { response }\end{array}$} & \multicolumn{4}{|c|}{$\begin{array}{l}\text { Knowledge } \\
\text { application }\end{array}$} \\
\hline & 4 & 3 & 2 & 1 & 4 & 3 & 2 & 1 & 4 & 3 & 2 & 1 & 4 & 3 & 2 & 1 & 4 & 3 & 2 & 1 \\
\hline $\begin{array}{l}\text { Experimenta } \\
(\mathrm{n}=34)\end{array}$ & 15 & 8 & 6 & 5 & 16 & 9 & 5 & 4 & 14 & 9 & 8 & 1 & 15 & 9 & 8 & 2 & 17 & 7 & 8 & 2 \\
\hline $\begin{array}{l}\text { Control group } \\
\mathrm{n}=33 \text { ) }\end{array}$ & 10 & 7 & 9 & 7 & 7 & 6 & 15 & 5 & 9 & 9 & 7 & 0 & 10 & 5 & 8 & 10 & 7 & 6 & 10 & 10 \\
\hline
\end{tabular}

The results of the above questionnaire showed that this teaching model effectively enhanced students' problem assessing ability, communication ability, judgment and thinking ability, emergency response ability, and knowledge application ability. The reasons were analyzed as follows: First of all, this teaching model broke through the limitations of learning venue and time. As an emerging virtual learning mode, this unrestricted internet-based teaching model accessible via computers, smart phones or other digital devices allowed students to adopt diversified learning methods in the form of video lectures, digital reading, interactive homework and online discussion, etc., especially available to obtain standardized nursing operation demonstrations and explanations at any time. Therefore, it improved student's academic performance and community nursing ability. Secondly, in virtue of virtual reality technology (VR) and other emerging devices, this teaching model allowed users' real-time exploration and manipulation of computer-generated artificial three-dimensional multimedia sensory 
environment was available in the form of data exchange, thereby further helping students acquire nursing practical knowledge together with VisibleBody software. The patient's anatomy was visualized through immersive VR to reduce operator's surgical errors, thereby enhancing students' problem-solving ability and emergency response ability.

\section{Conclusion}

In conclusion, OSCE-based community nursing teaching method proposed in this study can yield remarkable effects when applied in community nursing courses. It was proved by experiments that it not only continued to cultivate nurses' skills as the traditional teaching model, but also simulated different kinds of critical and urgent clinical scenarios in community nursing work, thereby meeting the requirements and needs of community nursing practice for nursing talents. The following conclusions are drawn from the teaching practice:

Hadoop can support supersized data, and the files stored in HDFS can support terabytes and petabytes of data. They play a vital role in community nursing online teaching course.

VisibleBody, available for comprehensively displaying the body system of the human body, can be used to set up community nursing online simulation courses, allowing students to take part in online learning activities at home and considerably promoting in community nursing teaching course design.

OSCE is designed for a comprehensive assessment of students for improving their core competence in practical application. Using OSCE for professional instruction of students is in accordance with the development of the discipline and is a new teaching practice in community nursing education.

\section{Acknowledgement}

This work was supported by 2017 Social Science Fund Projects of Hunan Province (17YBA361).

\section{$7 \quad$ References}

[1] Gao, B. Highly Efficient English MOOC Teaching Model Based on Frontline Education Analysis. International Journal of Emerging Technologies in Learning, 2019, vol. 14(6), pp. 138-146. https://doi.org/10.3991/ijet.v14i06.10160

[2] Miao, X.X., Zhu, X.L., Wang, L. The teaching design and implementation of practice teaching in community nursing under the new conditions of community health services. Chinese Nursing Management, 2010, vol. 10(12), pp. 32-34.

[3] De Villiers, J.C., Joubert, A., Bester, C.J. Evaluation of clinical teaching and professional development in a problem- and community-based nursing module. Curationis, 2004, vol. 27(1), pp. 82-93. https://doi.org/10.4102/curationis.v27i1.962 
[4] Safari, M., Yazdanpanah, B., \& Hatamipour, S. Learning outcomes and perceptions of midwifery students about peer-teaching and lecture method in gynecology and infertility course. Journal of Pedagogical Research, 2020, vol. 4(3), pp. 291-298. https://doi.org/10. 33902/jpr.2020063039

[5] Day-Black, C., Merrill, E.B., Konzelman, L., et al. Gamification: An Innovative TeachingLearning Strategy for the Digital Nursing Students in a Community Health Nursing Course. ABNF Journal, 2015, vol. 26(4), pp. 90-94.

[6] Vignato, J. A. , \& Guinon, T. . (2018). Healthstart: an innovative pilot model promoting diversity in nursing education. Nursing Education Perspectives, vol. 40(1), pp. 55-57. https://doi.org/10.1097/01.nep.0000000000000311

[7] Lambert, A.W., Harris, L.C., Wang, C.H., et al. Community-Based Breastfeeding Support with the Tiger Babies Breastfeeding Support Tent. Nursing for women's health, 2018, vol. 22(2), pp. 138-147. https://doi.org/10.1016/j.nwh.2017.12.007

[8] Im, E.O., Kong, E.H. What Is the Status Quo of Evidence-Based Community Health Nursing? Research and theory for nursing practice, 2017, vol. 31(2), pp. 156-178. https://doi. org/10.1891/1541-6577.31.2.156

[9] Zheng, Y., Xu, L.L., and Li, H.Y. A Practical Research on the Application of Students' Selforganized Tests in the Core Course Teaching of Nursing Students for Improving the Pass Rate of Nursing Tests. The ence Education Article Collects, 2018, vol. 15(13), pp. 103-104.

[10] Miao, H.L., Zhang, M. Reform of community nursing teaching method with professional ability as the core. Health Vocational Education, 2016, vol. 34(20), pp. 80-81.

[11] Lin, Z.Q. Application of sitcom performance in the teaching of community nursing. Journal of Mudanjiang Medical University, 2015, vol. 36(5), pp. 133-135

[12] Shen, R., Jin, R.H. Application of conception design realization operation teaching mode in community nursing. China Higher Medical Education, 2018, vol. 32(9), pp. 111-112.

[13] Jiao, L.M., Wang, H.H. Study on the Teaching Practice of Extracurricular Linkage of Internet Plus Community Health Education Volunteers. Northwest Medical Education, 2016, vol. 24(5), pp. 668-671.

[14] Mitchell, M.L., Jeffrey, C.A., Henderson, A., et al. Using an Objective Structured Clinical Examination for Bachelor of Midwifery students' preparation for practice. Women and Birth, 2014, vol. 27(2), pp. 108-113. https://doi.org/10.1016/j.wombi.2013.12.002

\section{Authors}

Haiyan Deng is a Lecturer in the School of Nursing, Xiangnan University, Chenzhou, China (denghaiyan202012@163.com).

Chunyan Li (Correspondence Author) is a professor in the School of Nursing, Hunan University of Chinese Medicine, Changsha, China (13975513618@163.com).

Article submitted 2021-03-11. Resubmitted 2021-04-20. Final acceptance 2021-04-21. Final version published as submitted by the authors. 